\title{
Oral contraceptive use before first birth and risk of breast cancer: a case control study Elina Hemminki*1, Tapio Luostarinen ${ }^{2}$, Eero Pukkala ${ }^{2}$, Dan Apter ${ }^{3}$ and Timo Hakulinen 2,4
}

Address: ${ }^{1}$ National Research and Development Center for Welfare and Health, Health Services Research, Helsinki, Finland, ${ }^{2}$ Finnish Cancer
Registry, Institute for Statistical and Epidemiological Cancer Research, Helsinki, Finland, ${ }^{3}$ Finnish Student Health Service and Family Federation
of Finland, Helsinki, Finland and ${ }^{4}$ Department of Public Health, University of Helsinki, Finland E-mail: Elina Hemminki* - elina.hemminki@stakes.fi; Tapio Luostarinen - tapio.luostarinen@cancer.fi; Eero Pukkala - eero.pukkala@cancer.fi;
Dan Apter - dan.apter@vaestoliitto.fi; Timo Hakulinen - timo.hakulinen@cancer.fi

*Corresponding author

Published: 5 August 2002

Received: 30 January 2002

BMC Women's Health 2002, 2:9

Accepted: 5 August 2002

This article is available from: http://www.biomedcentral.com/1472-6874/2/9

(c) 2002 Hemminki et al; licensee BioMed Central Ltd. This article is published in Open Access: verbatim copying and redistribution of this article are permitted in all media for any non-commercial purpose, provided this notice is preserved along with the article's original URL.

Keywords: oral contraceptives, breast cancer, case-control study, epidemiology

\begin{abstract}
Background: The aim of this study was first, to investigate whether women starting oral contraceptive $(\mathrm{OC})$ use at a young age and before first birth have an increased risk for breast cancer and second, to report difficulties encountered in studying long-term health impacts of medical technologies.
\end{abstract}

Methods: Breast cancers occurring up until 1997 among 37153 Helsinki students born between 1946 and 1960 were identified by record linkage from the Finnish Cancer Registry; for each cancer case, five age-matched random controls were picked from the same student population. Those who had used the Helsinki Student Health Service (HSHS) at least three times ( 150 cases and 316 controls) form the final study subjects. Data on $O C$ use and background characteristics were collected from patient records, and data on live births were derived from the population register. Odds ratios (OR) were adjusted for number of births, smoking and sports activity.

Results: Compared to the few non-users, $O C$ users had a higher risk of breast cancer: the adjusted OR was 2.1 ( $95 \%$ confidence interval I.I-4.2). Among OC users, no statistically significant differences in risk of breast cancer were found in regard to starting age or first birth, but small numbers made confidence intervals wide. Even though we had chosen students to be our study group, the population turned out to be unsuitable to answer our research question: most women had started their OC use old (at the age of 20 or later) and there were very few unexposed (almost all had used $O C$ and before their first birth).

Conclusions: Because adoption of the modern pattern of $O C$ use was not common among students, it is unlikely that the impact of early and extended OC use can be studied before 2010 , when women born in the 1960s are 40 to 50 years old.

\section{Background}

Epidemiological studies give varying results in regard to whether oral contraceptive (OC) use is a risk factor for breast cancer. A thorough meta-analysis based on epidemiological studies up to the mid-1990s concluded that women who have used combined OCs in the past 10 years 
are at a slightly increased risk of having breast cancer, although the excess cancers diagnosed tended to be localised $[1,2]$. Some of the later studies concluded that OC use is a risk factor for breast cancer [3-10], or is for some subgroups [11,12], while other studies have not [13-16]. Young women having used the pill for a long time before their first pregnancy have been identified as a potential risk group $[6,14,17,18]$, but currently there are not enough studies to prove or disprove the increased risk of breast cancer [19].

OCs were introduced into clinical use in the early 1960s. Their use spread rapidly, but in the beginning they were used mainly by women older than 20 years, after the first birth, and intermittently; that is, for short periods of time [20]. Over time the OC use patterns have radically changed in many countries: start in the teen-years, use for a long time before the first pregnancy, and continuous use have increased and the type of pill has changed [6,20-23]. In Finland, $7 \%$ of 16 -year-old girls and $22 \%$ of 18 -yearold girls used OCs in 1981; by the year 1989 figures had increased to $17 \%$ and $38 \%$ [24] and have remained high [25]. In 1997 one third of girls had experienced their first sexual intercourse by the age of 16 years [26] and in 1998 the mean age at having the first child was 28 years [27]

The original purpose of this study was to see whether women who started OC use young and before their first birth have an increased risk for breast cancer before menopause. The study was done among Finnish students who used the Helsinki Student Health Service (HSHS), and cancers were identified by record linkage to the Finnish Cancer Registry. However, as shown below, we ended up with a low study power, and a second purpose of this article is to report the reasons to it to help others designing studies on OC use and breast cancer.

\section{Subjects and methods}

This is a case control study among defined student populations. The first study base consisted of all Finnish female Helsinki University students from 1965 onwards who were born in the $1946-1960$ period $(n=28109)$ and were customers of the HSHS. The second study base was female students of other higher educational institutions in the Helsinki area who used the HSHS in 1980 or later $(\mathrm{n}=$ 9044). Most Helsinki students used the HSHS because belonging to the programme was compulsory and everyone had to pay the health service fee, and municipal public health care, with the exception of emergencies, was restricted to municipality residents. Students could use private services. The HSHS had very low fees for visits, and once students entered the system they usually used its services. In 1971, the first gynaecologists were employed by the HSHS.
To identify those who later got breast cancer, the data on the women in the study bases were linked to data in the Finnish Cancer Registry for 1967 to 1997 using unique personal identification (ID) numbers; since 1967 these ID-numbers have been given to everyone who has lived in Finland. The Finnish Cancer Registry has operated since 1953 and is based on compulsory notifications by physicians who diagnose a malignant disease; the data in this register were completed with information from hospitals, laboratory records and death certificates. The notification rate and accuracy of the registry are high [28]. Through the linkage, 396 cases were found. For each cancer case, five random controls (total 1980), matched for year of birth, were chosen from the same study bases.

A requirement of at least three visits to HSHS, other than the initial health check-up or a visit to a dentist or an ophthalmologist, was set to exclude women who had sought their health care and OCs from other sources. Number of visits was determined by manually searching the HSHS archives; 153 cases and 314 controls had at least three visits. For 14 cases no controls remained. For them, one new control, born in the same year, was randomly picked from the 388 leftover controls (i.e. controls whose matched case had not used services at least three times). The dates of live births and women's vital status were obtained by record linkage to the population register. Cases whose first HSHS visit was after the breast cancer diagnosis $(n=3)$ and controls who had died before or whose first visit was after the time of the diagnosis of breast cancer in the case $(n=12)$ were excluded. Altogether 150 cases and 316 controls remained for analysis. Two cases had a carcinoma in situ, others a malignant tumour; $80 \%$ were ductal carcinomas. By the end of 1997, 17 women in the case group (11\%) had died of breast cancer.

Data on exposure to OCs, reproductive history and background characteristics were collected from the HSHS patient records. A trained research nurse blind to the casecontrol status abstracted the data. To identify OC use, a list of all OCs on the Finnish market in the 1962-1985 period was made with the help of old drug catalogues. The HSHS kept continuous patient records in which all prescriptions were marked. Information on OC use while an HSHS customer was searched for from physicians' notes and referral notes to the laboratory for PAP smears (at that time, PAP smears were recommended to be regularly done for OC users). In 1971 the HSHS introduced health status questionnaires to be filled in at the first visit, including a standard question on current and past OC use. Overall, $29 \%$ of women (25\% of cases and $30 \%$ of controls) had a note indicating OC use before entering HSHS. To describe the women, the duration of OC use was calculated by summing up the months from OC prescriptions, and the 
estimates given in the records on prior use and on OCs prescribed outside the HSHS.

Using all available data in HSHS documents, the year of start of OC use was calculated. Exposure data were collected for all years up to the until one year prior to the breastcancer diagnosis of the case. For each woman the following exposure data were constructed: OC use, age starting OC use, and OC use before first live birth. Use of OCs was classified into three classes: no (no, likely not), yes (yes, likely yes), and not recorded. Women with any documented use were included in the 'yes' class; the shortest duration was one month. The group 'not recorded' was a mixed bag of women for whom there was some indication of OC use, but no details of use ware available. It included women who had a private gynaecologist or had received an OC prescription, but who in later visits indicated no OC use.

For one analysis, OC users were classified into the following group: 1) started before the age of 23 years and before first pregnancy, 2) other users (started older or after first pregnancy or information on these characteristics was lacking), 3) others. The cut-off point of 23 years was chosen to get a reasonable number of women in each group.

Odds ratios (OR) and $95 \%$ confidence intervals (CI) were estimated using conditional logistic regression [29] with GLIM 4 software [30]. The following data on potential confounders were available in the patient records: study discipline, weight and height, menarche age, menstruation cycle (average length and duration of bleeding), smoking, alcohol use, participation in sports (either competitive or other) at the first visit, and pregnancies at any time while using the HSHS. Data on live births were obtained from the population register. The odds ratios were adjusted for smoking (never, ever, unknown), sports (no sports, sports, unknown), and for parity and age at delivery.

\section{Results \\ Breast cancer}

The cases and controls were similar in terms of most studied background characteristics, but there were more controls who were active in sports (Table 1). The proportions of women having had births were relatively similar among cases (73 percent) and controls (67 percent) and the cases and controls had their first child about at the same age (Table 1). In addition to the variables shown in Table 1, we compared the cases and controls in terms of how soon they entered the HSHS after starting their studies (for $60 \%$ of cases and $64 \%$ of controls the difference between the first visit and starting year was less than 2 years), last visit to the HSHS (56\% and 53\% before 1980), study institute (University of Helsinki for 90\% and 93\%), distribution of weight at first visit (similar), distribution of height (similar), distribution of menarchial age (similar), distribution (similar) and mean (both 28.5 days) of the length of menstrual cycle, and distribution (similar) and mean (5.1 and 5.0 days) of the duration of menstrual period. Record linkage to the population register showed that cases somewhat more often had children (not statistically significant).

Most study women had used OCs while customers of the HSHS or before that, and started the use at the age of 20 or later. The mean age was 22.6 years $(\mathrm{SD}=3.2)$ among cases and 22.3 (3.2) among controls. Starting young increased by time: $3 \%$ of the women born between 1947 and $1950(n=220), 10 \%$ of those born between 1951 and $1955(\mathrm{n}=138)$, and $24 \%$ of those born between 1956 and $1960(\mathrm{n}=110)$ started before 20 years of age. Most women had started their OC use before first birth. $80 \%$ of OC users had made last visit to HSHS when they were 25 years or younger. The length of OC use as noted in the records was 3 years or less among most women, with means 2.6 years $(S D=2.5)$ for cases and $2.9(2.3)$ for controls.

Compared to those few women who had not used OC, OC users had a higher risk of breast cancer (Table 2). Adjustment for confounders did not abolish the difference. Among OC users, those who had started young did not have a higher risk of breast cancer than those who had started older ( 25 or more) (Table 3 ). There was also no difference in the risk of breast cancer in regard to whether the use was started before or after the first birth, or in regard to having not given birth, Table 4 . There was no difference in the risk of breast cancer among women who had been pregnant while in the HSHS in regard to whether they had used OCs before or only after the first pregnancy.

When OC users were compared in terms of the time interval from the first use to the first birth, no statistically significant differences in the risk of breast cancer were found. When users having the time interval 1 to 5 years were used as the reference category, the adjusted odds ratio for the 6to 10 - year interval was $0.7(95 \% \mathrm{CI} 0.4,1.3)$ and for the 11 - to 20 - year interval it was $0.8(0.3,1.9)$.

When we compared OC users by the age at start of OC use and relation to first pregnancy, no statistically significant differences were found. Women who started young (less than 23 years) and before their first pregnancy did not have a higher risk (OR 1.1, 95\% CI 0.7, 1.8) than other OC users.

\section{Feasibility}

University students were chosen as the study population because we assumed them to be the first to adopt the 
Table I: Percentage distributions or means (standard deviation, SD) of cases with breast cancer and their controls by study characteristics in the HSHS cohort

\begin{tabular}{|c|c|c|}
\hline \multirow[t]{2}{*}{ Study characteristic } & \multicolumn{2}{|l|}{ Percentage or mean } \\
\hline & Cases $n=150$ & Controls $n=316$ \\
\hline \multicolumn{3}{|l|}{ Year of birth, \% } \\
\hline $1946-1950$ & 48 & 47 \\
\hline $1951-1955$ & 29 & 30 \\
\hline $1956-1960$ & 23 & 24 \\
\hline \multicolumn{3}{|l|}{ First visit at the HSHS, \% } \\
\hline $1965-1969$ & 19 & 14 \\
\hline $1970-1974$ & 39 & 41 \\
\hline $1975-1995$ & 43 & 45 \\
\hline \multicolumn{3}{|l|}{ Smoking, \% } \\
\hline Current & 23 & 29 \\
\hline Quitted & 3 & 6 \\
\hline Never & 58 & 55 \\
\hline No information & 16 & 10 \\
\hline \multicolumn{3}{|l|}{ Alcohol use, $\%$} \\
\hline Moderate or heavy & 17 & 18 \\
\hline Slight & 37 & 38 \\
\hline No & 9 & 15 \\
\hline No information & 37 & 29 \\
\hline \multicolumn{3}{|l|}{ Sports, \% } \\
\hline Active & 21 & 35 \\
\hline No & 53 & 44 \\
\hline No information & 26 & 21 \\
\hline Weight (kg), mean (SD) & $57.0(7.1)$ & $56.2(7.6)$ \\
\hline Height $(\mathrm{cm})$, mean $(\mathrm{SD})$ & $166(5.2)$ & $165(5.6)$ \\
\hline Age at menarche (in years), mean (SD) & $12.8(1.2)$ & $12.7(1.2)$ \\
\hline Contraception *, \% & 94 & 88 \\
\hline Any births $\ddagger$, \% & 73 & 67 \\
\hline \multicolumn{3}{|l|}{ Age at first delivery $\S$ (in years), \% } \\
\hline $18-24$ & 17 & 20 \\
\hline $25-29$ & 48 & 49 \\
\hline $30-34$ & 29 & 26 \\
\hline $35-41$ & 5 & 5 \\
\hline Mean (SD) & $28.1(3.7)$ & $27.7(4.1)$ \\
\hline
\end{tabular}

*Any method recorded by the HSHS at any time. $\ddagger$ Births in Central Population Register before year of case's diagnosis. §Delivery before year of case's diagnosis.

Table 2: Odds ratios (OR) with $95 \%$ confidence intervals (CI) for breast cancer related to the use of oral contraceptives (OCs) while customer of the HSHS or before that.

\begin{tabular}{|c|c|c|c|c|c|c|c|}
\hline \multirow[t]{2}{*}{ OC user } & \multicolumn{2}{|c|}{ Cases } & \multicolumn{2}{|c|}{ Controls } & \multirow{2}{*}{$\begin{array}{c}\text { Crude } \\
\text { OR }\end{array}$} & \multicolumn{2}{|c|}{ Adjusted* } \\
\hline & $n$ & $\%$ & $\mathrm{n}$ & $\%$ & & OR & $95 \% \mathrm{Cl}$ \\
\hline No $†$ & 15 & 10 & 57 & 18 & I & I & \\
\hline Yes & 114 & 76 & 222 & 70 & 2.1 & 2.1 & $(I . I, 4.2)$ \\
\hline Not recorded & 21 & 14 & 37 & 12 & 1.9 & 1.6 & $(0.6,4.0)$ \\
\hline Total & 150 & 100 & 316 & 100 & & & \\
\hline
\end{tabular}

*Adjusted for parity and age at delivery (no births before year of case's diagnosis, birth before 25 years, other), sports (no sports, sports, unknown), and smoking (never, ever, unknown). $†$ Reference group. 
Table 3: Odds ratios (OR) with $95 \%$ confidence intervals $(\mathrm{Cl})$ for breast cancer related to age at start of oral contraceptive (OC) use $\ddagger$.

\begin{tabular}{|c|c|c|c|c|c|}
\hline \multirow[t]{2}{*}{ Age at start of $O C$ use (in years) } & \multirow{2}{*}{$\begin{array}{c}\text { Cases } \\
n\end{array}$} & \multirow{2}{*}{$\begin{array}{c}\text { Controls } \\
n\end{array}$} & \multirow{2}{*}{$\begin{array}{c}\text { Crude } \\
\text { OR }\end{array}$} & \multicolumn{2}{|c|}{ Adjusted* } \\
\hline & & & & OR & $95 \% \mathrm{Cl}$ \\
\hline $16-19$ & 11 & 36 & 0.6 & 0.5 & $(0.2,1.6)$ \\
\hline $20-24$ & 77 & 140 & 0.9 & 0.9 & $(0.5,1.9)$ \\
\hline$\geq 25 \dagger$ & 21 & 40 & 1 & I & \\
\hline Age missing & 5 & 6 & .. & .. & \\
\hline
\end{tabular}

¥ Women missing information about OC use or (2I cases and 37 controls) or not having used OCs while in the HSHS (I5 cases and 57 controls) were excluded. *Adjusted for parity and age at delivery (no births before year of case's diagnosis, birth before 25 years, other), sports (no sports, sports, unknown), and smoking (never, ever, unknown). † Reference group.

Table 4: Odds ratios (OR) with $95 \%$ confidence intervals $(\mathrm{Cl})$ for breast cancer associated with use of oral contraceptives (OCs) in relation to the first birth‡.

\begin{tabular}{|c|c|c|c|c|c|}
\hline \multirow[t]{2}{*}{ Use of $O C$} & \multirow{2}{*}{$\begin{array}{c}\text { Cases } \\
\mathrm{n}\end{array}$} & \multirow{2}{*}{$\begin{array}{c}\text { Controls } \\
n\end{array}$} & \multirow{2}{*}{$\begin{array}{c}\text { Crude } \\
\text { OR }\end{array}$} & \multicolumn{2}{|c|}{ Adjusted* } \\
\hline & & & & OR & $95 \% \mathrm{Cl}$ \\
\hline User after $\left.\right|^{\text {st }}$ birth $\dagger$ & 7 & 12 & 0.8 & 0.8 & $(0.2,2.5)$ \\
\hline User before Ist birth & 74 & 143 & 1.1 & 1.0 & $(0.5,1.7)$ \\
\hline User, no births & 32 & 62 & I & 1 & \\
\hline Order of use and births ${ }^{* *}$ not known & $\mathrm{I}$ & 5 & & & \\
\hline
\end{tabular}

¥ Women missing information about OC use or ( 21 cases and 37 controls) or having not used OCs while in the HSHS (I5 cases and 57 controls) were excluded. *Adjusted for sports (no sports, sports, unknown) and smoking (never, ever, unknown). $†$ Reference group. ${ }^{* *}$ Chronological order of the first delivery and start of $O C$ use.

modern pattern of OC use: starting young and having long use before first birth. Furthermore, many of them had used only one service that has feasible archiving system, as well as computerised registers with unique personal ID-numbers, making record linkage easy. We matched the cases and controls by age and they all were university students. Our assumption about there being many young starters in this data set turned out to be wrong: only among the youngest cohort, born in the latter half of the 1950 s, was OC use before the age of 20 years common. We also had very few non-users. OC use seems to have spread among students very rapidly and almost everyone at lest experimented with them.

\section{Discussion}

The hypothesis that OC use is related to breast cancer in young age received limited support. But no clear relation was found with starting age or starting before first birth. We could not study the impact of the length of OC use because we had no data on the women's OC use after their student years. A side finding was that cases were less likely to have been active in sports, either competitive or recrea- tional, at their first visit. This is in accordance with earlier literature $[30,31]$.

Several methodological problems, however, weaken these findings. The main problems were, as described above, small numbers of young starters, few non-users, and few starters after first birth. Furthermore, because of our criterion of at least 3 visits to HSHS, we very likely proportionally selected out more non-users than users of OC: one of the important reasons for HSHS visits was to get OC. Because more control $(84 \%)$ than case women $(63 \%)$ were excluded because of this limit, we were likely to proportionally exclude more non-users among the controls. Accordingly our analysis may underestimate the relation between OC use and breast cancer. In hindsight, the drawbacks of the potential bias caused by this criterion surpass the benefits, and we should not have used such a criterion.

A strength of our study was that the data on exposure were based on patient records. Because of the eligibility requirement of at least three visits, it is likely that we have relatively complete information on OC use while the 
women were students in Helsinki. The information on their status before they entered the HSHS was based on women's interviews as noted in the patient records, and may be incomplete. These inaccuracies in exposure data weaken the comparisons between different user groups. The comparison between cases and controls was made with the assumption that the omissions were similar in these two groups. We excluded women who had breast cancer before their first HSHS visit, but women who had it between the first and the third visit were included. Inclusion of these women makes our finding of an increased risk for breast cancer due to $\mathrm{OC}$ use conservative. On the other hand, if the women classified as 'OC use not recorded' were in fact non-users, the association between OC use and breast cancer becomes much smaller.

Most earlier case-control studies on OC use have relied on women's (or their relatives') memory of OC use. Compared to such an approach, our information on exposure is more accurate in terms of starting age and relation to the first birth (and type of drug, not analysed here). But we could not adjust for current OC use, which has been found to be a risk factor for breast cancer [1]. Nor do we have data of the length of OC use.

Because adoption of the modern pattern of OC use was not common among students, it is unlikely that the impact of early and extended OC use can be studied before 2010, when women born in the 1960s are 40 to 50 years old. Studies before that have to focus on either the impact on very early breast cancer, which is rare and may be different (e.g. due to genetic predisposition) from breast cancer emerging around menopause, or focus on women whose OC-use patterns are very different from those of other women. Such women are likely to differ from others on many dimensions and confounding by unknown factors may be large.

The case of OC use well illustrates the difficulty of evaluating the long-term health impact of medical technologies. The true impacts may be revealed only after decades of use, and often only after the technology is no longer in use. In the case of OCs, the technology itself is still in wide use, but the use patterns, user groups and chemical composition of the drugs have changed. The results of our study concern a population of women who started OC use before their first birth and pregnancy, who were much older than the current OC-user population, and who used OCs differing in composition and chemical strength from those used today.

\section{Conclusions}

The hypothesis that OC use is related to breast cancer in young age received only limited support. Our study women commonly used OC before first birth, but started their use at a later age. The impact of young starting age in this population can be studied only later, e.g. after a decade or so.

\section{Competing Interests \\ None declared}

\section{Authors' Contributions}

EH: Planned the study and was responsible for data collection and reporting.

\section{TL: Did the statistical analyses}

EP: Participated in the planning of the study and statistical analyses

DA: Participated in the planning of the study and data collection

\section{TH: Participated in the statistical analyses}

All authors participated in writing the manuscript and have read and approved the final version.

\section{Acknowledgements}

We thank Susanna Kaipainen and Nina Apter for their help in collecting data, and Kati Tanninen for her secretarial help.

\section{References}

I. Collaborative Group on Hormonal Factors in Breast Cancer: Breast cancer and hormonal contraceptives: collaborative reanalysis of individual data on $\mathbf{5 3 2 9 7}$ women with breast cancer and 100239 women without breast cancer from 54 epidemiological studies. Lancet 1996, 347:1713-1727

2. Collaborative Group on Hormonal Factors in Breast Cancer: Breast cancer and hormonal contraceptives: further results. Contraception 1996, 54: IS-I06S

3. Palmer JR, Rosenberg L, Rao RS, Srom BL, Warshauer ME, Harlap S, Zauber A, Shapiro S: Oral contraceptive use and breast cancer risk among African-American women. Cancer Causes Control 1995, 6:32|-33|

4. Brinton LA, Gammon MD, Malone KE, Schoenberg JB, Daling JR, Coates $\mathrm{RJ}$ : Modification of oral contraceptive relationships on breast cancer risk by selected factors among younger women. Contraception 1997, 55:197-203

5. Brinton LA, Brogan DR, Coates RJ, Swanson CA, Potischman N, Stanford JL: Breast cancer risk among women under 55 years of age by joint effects of usage of oral contraceptives and hormone replacement therapy. Menopause I998, 5:|45-I5 I

6. Tryggvadóttir L, Tulinius H, Gudmundsdottir GB: Oral contraceptive use at a young age and the risk of breast cancer: an Icelandic, population-based cohort study of the effect of birth year. Brit J Cancer 1997, 75: |39-|43

7. Chie WC, Li CY, Huang CS, Chang KJ, Yen ML, Lin RS: Oral contraceptives and breast cancer risk in Taiwan, a country of low incidence of breast cancer and low use of oral contraceptives. Int J Cancer 1998, 77:219-223

8. Ursin G, Ross RK, Sullivan-Halley J, Hanish R, Henderson B, Bernstein $\mathrm{L}$ : Use of oral contraceptives and risk of breast cancer in young women. Breast Cancer Res $\operatorname{Tr}$ 1998, 50:175-184

9. Fioretti F, Tavani A, Bosetti C, La Vecchia C, Negri E, Barbone F, Talamini R, Franceschi S: Risk factors for breast cancer in nulliparous women. Brit J Cancer 1999, 79:1923-1928

10. Shapiro S, Rosenberg L, Hoffman M, Truter H, Cooper D, Rao S, Dent D, Van Zyl J, Katzenellenbogen J, Bailie R: Risk of breast cancer in relation to the use of injectable progestogen contraceptives 
and combined estrogen/progestogen contraceptives. Am J Epidemiol 2000, I 5 I:396-403

II. Ursin G, Henderson BE, Haile RW, Pike MC, Zhou N, Diep A, Bernstein $L$ : Does oral contraceptive use increase the risk of breast cancer in women with BRCAI/BRCA2 mutations more than in other women? Cancer Res 1997, 17:3678-368।

12. Marcus PM, Baird DD, Millikan RC, Moorman PG, Qaqish B, Newman $B$ : Adolescent reproductive events and subsequent breast cancer risk. Am J Public Health 1999, 89: I 244- 247

13. Tümasson $\mathrm{H}$, Tümasson $\mathrm{K}$ : Oral contraceptives and risk of breast cancer. A historical prospective case-control study. Acta Obstet Gyne Scan 1996, 75:157-16|

14. Hankinson SE, Colditz GA, Manson JE, Willett WC, Hunter DJ, Stampfer MJ, Speizer FE: A prospective study of oral contraceptive use and risk of breast cancer (Nurses' Health Study, United States). Cancer Causes Control 1997, 8:65-72

15. Beral V, Hermon C, Kay V, Hannaford P, Darby S, Reeves G: Mortality associated with oral contraceptive use: 25 year follow up of cohort of $\mathbf{4 6 0 0 0}$ women from Royal College of General Practitioners' oral contraception study. Brit Med J 1999, 3 18:96-100

16. Tavani A, Gallus S, La Vecchia C, Negri E, Montella M, Dal Maso L, Franceschi S: Risk factors for breast cancer in women under $\mathbf{4 0}$ years. Eur J Cancer 1999, 35: | 36 |- I 367

17. Olsson H, Borg Å, Fernö M, Möller TR, Ranstam J: Early oral contraceptive use and pre menopausal breast cancer - $A$ review of studies performed in Southern Sweden. Cancer Detect Prev | 99|, | 5:265-27|

18. Velentgas P, Daling JR: Risk factors for breast cancer in younger women. J Nat Cancer Inst Monog 1994, 16:15-22

19. McPherson K: Type 3 errors, pill scares, and the epidemiology of oral contraception and health. J Epidemiol Commun $H$ 1999, 53:258-260

20. Institute of Medicine: Oral Contraceptives \& Breast Cancer. Washington, D.C. National Academy Press 1991

21. Hunt $\mathrm{K}$ : The first pill-taking generation: past and present use of contraception amongst a cohort of women born in the early 1950s. Brit J Fam Plan 1990, 16:3-15

22. Gerstman BB, Gross TP, Kennedy DL, Bennett RC, Tomita DK, Stadel BV: Trends in the content and use of oral contraceptives in the United States. Am J Public Health 1991, 81:90-96

23. Ranstam J, Olsson $\mathrm{H}$ : Oral contraceptive use among young women in Southern Sweden. J Epidemiol Commu Health 1993, 47:32-35

24. Rimpelä $A$, Rimpelä $M$, Kosunen $E$ : Use of oral contraceptives by adolscents and its consequences in Finland in 198I-199 I. Brit Med J 1992, 305: 1053-1057

25. Kosunen E, Huhtala H, Rimpelä A, Rimpelä M, Liinamo A: Public scare has not deterred Finnish teenagers from using oral contraceptives. Brit Med J 1997, 3 I 4:1348

26. Kosunen E, Rimpelä M, Liinamo A, Jokela J, Vikat A, Rimpelä A: Nuorten seksuaalikäyttäytyminen Suomessa 1996-1997. Suom LääkLehti 53:3353-3350

27. Koskinen R, Meriläinen J, Gissler M, Virtanen M: Finnish Perinatal Statistics 1997-1998. Helsinki: Statistical Report 4I, STAKES, 1999, 14

28. Teppo L, Pukkala E, Lehtonen M: Data quality and quality control of a population-based cancer registry. Acta Oncol I 994, 33:365369

29. Breslow N, Day N: Statistical methods in cancer research. Volume I. The analysis of case-control studies. Lyon: International Agency for Research on Cancer, 1980

30. Francis B, Green M, Payne E, eds: The GLIM System. Release 4 manual. Oxford: Clarendon Press 1993

31. Thune I, Brenn T, Lund E, Gaard M: Physical activity and the risk of breast cancer. N Engl J Med I997, 336:1269-1275

32. Latikka P, Pukkala E, Vihko V: Relationship between the risk of breast cancer and physical activity An epidemiological perspective. Sports Med 26:133-143

\section{Pre-publication history}

The pre-publication history for this paper can be accessed here: http://www.biomedcentral.com/1472-6874/2/9/prepub

Publish with BioMed Central and every scientist can read your work free of charge

"BioMedcentral will be the most significant development for disseminating the results of biomedical research in our lifetime." Paul Nurse, Director-General, Imperial Cancer Research Fund

Publish with BMC and your research papers will be:

- available free of charge to the entire biomedical community

- peer reviewed and published immediately upon acceptance

- cited in PubMed and archived on PubMed Central

- yours - you keep the copyright 